\title{
Design Thinking: oficinas para inovação e empoderamento feminino
}

\author{
Lauana Maria C. de Oliveira, Rhenara Alves Oliveira, Anna Beatriz Marques \\ Universidade Federal do Ceará (UFC) - Campus Russas \\ Russas - CE - Brasil \\ \{lauanacartaxo, rhenaraalves21\}@alu.ufc.br, beatriz.marques@ufc.br
}

\begin{abstract}
In a period of technological revolution, in which new tools arem emerging every day to solve the demands of humanity and to set new trends, the social struggles also need to follow evolution. Innovation and technology bring revolutionary opportunities, but female representation is still insufficient in science and technology. Design Thinking is an approach to innovation that suggests tools to integrate understanding about people' needs into the design of innovative technologies. The aim of this paper is to present an experience with conducting Design Thinking workshops to create innovative technological solutions to empower women. The methodology adopted involved holding the proposed workshop in three technology events where each workshop addressed a theme related to women's protagonism.
\end{abstract}

Resumo. Em tempos de revolução tecnológica, em que, a cada dia, novas ferramentas surgem para solucionar demandas da humanidade e estipular novas tendências, as lutas sociais também precisam acompanhar a evolução. A inovação e tecnologia trazem oportunidades revolucionárias, mas a representação feminina ainda é insuficiente nas áreas da ciência e tecnologia. O Design Thinking é uma abordagem para inovação que sugere ferramentas para integrar o entendimento sobre as necessidades das pessoas ao design de tecnologias inovadoras. O objetivo deste artigo é apresentar uma experiência com a condução de oficinas de Design Thinking para a criação de soluções tecnológicas inovadoras no empoderamento de mulheres. A metodologia adotada envolveu a realização da oficina proposta em três eventos de tecnologia, onde cada oficina abordou um tema baseado no protagonismo feminino.

\section{Introdução}

A inovação e tecnologia trazem oportunidades sem precedentes, mas as mulheres ocupam de maneira insuficiente áreas da ciência e tecnologia (ONU, 2019). Então é de extrema importância que mulheres sejam estimuladas a seguir na área de Tecnologia da Informação (TI). Como uma tentativa de reverter alguns dos preconceitos e obstáculos impostos às mulheres, diversas instituições e organizações formularam novas estratégias para atrair e incentivar a participação de mulheres na área da TI (Louzada et al., 2014). É imprescindível que ações sejam realizadas para incentivo à participação de mulheres na Computação

Este artigo apresenta um relato de experiência do projeto de pesquisa e extensão Meninas Digitais do Vale, no qual foram realizadas oficinas de Design Thinking com o intuito de idealizar soluções tecnológicas para o empoderamento feminino. O Design Thinking pode 
ser adotado para integrar diferentes perspectivas de áreas como Ciência da Computação, Ciências Sociais e Design por meio de sua variedade de técnicas (Fawcett et al. 2013).

O objetivo das oficinas consistiu em unir a aplicação de técnicas de Design Thinking à discussão sobre problemas e soluções a respeito do empoderamento feminino. As oficinas foram conduzidas com públicos de diferentes faixas etárias e perfis: (i) estudantes de ensino médio; (ii) profisssionais da área de TI; e (iii) estudantes de graduação em Engenharia de Software e Ciência da Computação. Almeja-se que este relato de experiência e os resultados obtidos com a realização das oficinas possam contribuir para futuras pesquisas em projetos com temática similar, além de estimular as mulheres a buscarem o empoderamento.

\section{Oficinas de Design Thinking: Planejamento e Condução}

A metodologia Design Thinking (DT) consiste em conseguir entender o que o usuário de um produto, ou serviço deseja, podendo ser adotada em diversos segmentos (Pagani, 2018). O DT apresenta uma série de técnicas e ferramentas colaborativas utilizadas para a coleta e classificação de informações.

Esta seção relata o planejamento e condução de três oficinas no âmbito deste projeto, onde não houve repetição de participantes. A oficina consiste em aplicar técnicas de DT como: Sessões Generativas, um encontro no qual se convida usuários envolvidos no tema do projeto, para que compartilhem suas experiências e visões sobre o tema do projeto. Brainstorming, uma técnica de ideação que tem como objetivo explorar os talentos criativos em um grupo, gerando um grande volume de novas ideias. Persona, personagem fictício baseado em dados reais sobre comportamento e características de usuário, assim como suas histórias pessoais, motivações e objetivos. Prototipação, modelos representativos que permitem demonstrar como um produto ou serviço deve funcionar na prática. Encenação, simulação de situação, que pode representar a interação de uma pessoa com um dispositivo ou um diálogo entre indivíduos para representar a utilização de um determinado serviço. (Vianna et al. 2012). As técnicas descritas nesta seção foram adotadas nas oficinas de DT conduzidas e relatadas neste artigo.

As três oficinas seguiram procedimentos metodológicos comuns iniciando com a apresentação, por meio de slides e projetor, sobre inovação, DT e as técnicas a serem adotadas na oficina. Esta apresentação é realizada por duas alunas do projeto Meninas Digitais do vale que conduzem a oficina. São discutidos temas sobre empoderamento feminino e carência da participação de mulheres na área tecnologia e são apresentados alguns exemplos de aplicativos que são voltados para o público feminino.

Os participantes foram divididos em equipes, assegurando que em todas as equipes houvessem participantes do sexo feminino. Nas três oficinas seguiu-se um roteiro, para a utilização das técnicas descritas acima. Para cada participante do sexo feminino foi entregue um post-it e solicitado que a participante escrevesse um relato de uma situação real ou desafio enfrentado referente ao tema da oficina. Em seguida, os post-its foram trocados entre as equipes, para que todos tivessem conhecimento das adversidades encaradas no dia a dia de cada participante. Com isso foi possível que os grupos já divididos, pudessem realizar um brainstorm entre os seus participantes, gerando ideias para o desenvolvimento dos aplicativos.

As técnicas de DT foram aplicadas com o intuito de projetar soluções tecnológicas para um ou mais desafios relatados nos post-its recebidos por cada equipe. As equipes receberam templates e materiais de apoio como papéis, tesoura, canetas coloridas, cola e cartolina para a aplicação das técnicas de personas e prototipação. Após o momento de criação, 
cada equipe apresentou sua solução, por meio de encenação, mostrando o funcionamento do aplicativo e dando uma breve explicação sobre a ideia pensada.

$\mathrm{Na}$ primeira oficina realizada houve a aplicação de um questionário, que buscava coletar um feedback dos participantes sobre o entendimento dos participantes em relação aos temas: design thinking e empoderamento feminino, além da forma como eles utilizaram as técnicas de DT ao longo da oficina. Na segunda e terceira oficina, não houve tempo suficiente para a aplicação dos questionários, sendo relatados neste artigo somente as ideias dos aplicativos projetados.

A primeira oficina foi conduzida em 2018 durante uma semana temática dos cursos de Engenharia de Software e Ciência da Computação na universidade Federal do Ceará, aberta ao público externo. Esta oficina teve a participação de 25 estudantes de ensino médio e graduação. Sendo 11 homens e 14 mulheres. Teve a duração de três horas, onde foi possível a aplicação de questionário com o intuito de receber o feedback da oficina. A oficina abordou a temática sobre o "empoderamento feminino" e, como resultado foram projetados cinco aplicativos pelas equipes.

A segunda oficina foi ofertada em 2019 durante o evento da google de tecnologia direcionado à mulheres e realizado em comemoração ao Dia Internacional da Mulher. O projeto foi convidado a ofertar a oficina neste evento. Nesta oficina, participaram 30 mulheres da área de TI entre estudantes e profissionais da indústria e teve a duração de duas horas. O tema da oficina foi "desafios diários das mulheres" e foram projetados seis aplicativos.

A terceira oficina foi realizada em 2019, durante uma semana temática dos cursos de Engenharia de Software e Ciência da Computação na universidade Federal do Ceará, aberta ao público externo. Esta oficina contou com a participação de 25 pessoas, sendo elas estudantes e visitantes. A duração da oficina foi uma hora e seu tema foi o "fortalecimento da participação feminina na universidade". As equipes projetaram cinco aplicativos.

\section{Ideias de aplicativos}

Foram levantados problemas enfrentados por mulheres que poderiam ser minimizados pelo uso de um aplicativo, ajudando ao seu cotidiano. Ao final de cada oficina as equipes apresentaram suas soluções idealizadas em protótipos. Foram idealizados um total de 16 aplicativos, onde foi realizado uma análise pelas responsáveis da oficina, onde foi visto as ideias apresentadas em cada um, as semelhanças e diferenças, com isso foram selecionados 6 aplicativos.

As ideias envolveram aplicativos para caminhadas compartilhadas, prática de ciclismo em ambiente seguro, relato de problemas e desafios diários, recebimento de apoio e ajuda em situações desafiadoras, história de mulheres na computação, divulgação de eventos voltados para o público feminino, publicação de artigos, capacitação, troca de experiências e ensino de programação. A Figura 1 ilustra algumas ideias de aplicações, organizadas em três categorias. 


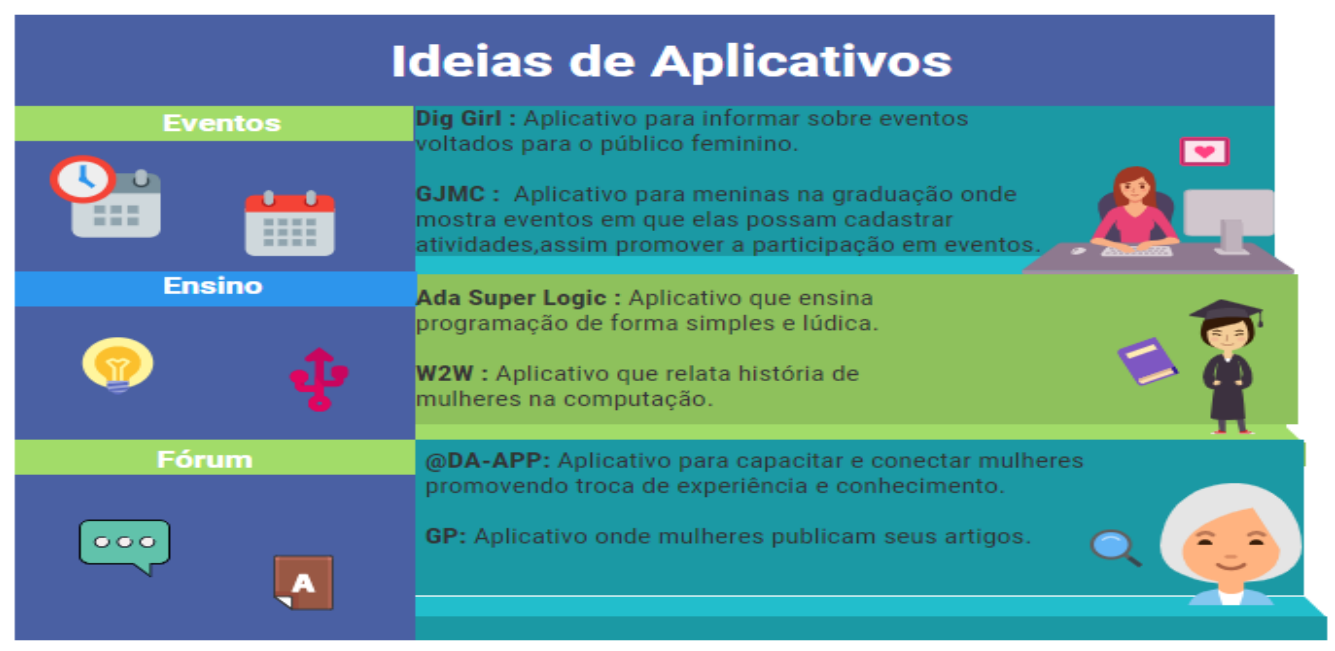

Figura 1. Ilustração das Ideias de Aplicativos

As oficinas abordaram diferentes temáticas relacionadas ao empoderamento feminino. As ideias que emergiram da oficina apresentam potencial para resolver os desafios e problemas explorados nos diferentes temas.

Os aplicativos idealizados Dig Girl e GJMC foram voltados para eventos onde o público alvo são mulheres. O Dig Girl você selecionaria a área de interesse por exemplo tecnologia, e ele mostraria os eventos. O GJMC é direcionado para meninas que estão em graduação desenvolvendo atividades e que tem interesse em apresentar, ele direcionaria eventos para as graduandas onde pudessem cadastrar suas atividades. Para auxiliar no ensino da computação o aplicativo Ada Super Logic ensinaria a programação através de jogos de forma lúdica. $\mathrm{O}$ W2W seria um aplicativo onde contaria a história de mulheres na computação e suas contribuições para assim inspirar meninas a seguir na área. Os fóruns são espaços interativos e agradáveis de discussão onde membros podem compartilhar ou fazer perguntas sobre opiniões, dicas e experiências, o aplicativo @DA-APP foi idealizado para promover debates por meio de mensagens publicadas abordando temas diversos. O GP seria um aplicativo para publicar artigos de diversas áreas escritos por mulheres.

\section{Feedback dos participantes}

Nos questionários fornecidos foram escritos comentários sobre os pontos que mais despertaram o interesse na oficina. É possível destacar os seguintes: "Algumas técnicas apresentadas foram novas para mim. Achei muito legal a dinâmica de pensar em um aplicativo para solucionar problemas relatados pelas mulheres", "A oficina foi muito interessante em abordar a mulher na tecnologia", "[pontos positivos] Interação com outras pessoas, possibilidade de criar aplicação, visualizar novas ideias"

O aprendizado e a experiência que a oficina propiciou foi analisado, mostrando que a oficina contribui para o entendimento do Design Thinking, a aplicação de suas técnicas e que houve uma contribuição para criação de soluções inovadoras para o empoderamento feminino. Os resultados indicam que a integração de meninas na computação é fundamental para assegurar a participação nas áreas de ciência e tecnologia. $\mathrm{O}$ primeiro passo é perceber e se conscientizar de que há uma necessidade de incluir mulheres nas áreas de atuação que miram a sociedade do futuro e usar a tecnologia como uma aliada.

Considerando que a Computação abrange diversas áreas além da programação, conduzir oficinas que abrangem áreas como Interação Humano-Computador e Inovação 
Tecnológica podem atrair novos talentos para a área. Ademais, abordar temas relacionados ao empoderamento feminino, pode atrair novas mulheres para a área. Assim, os resultados indicam que a oficina possui potencial para apresentar a área de Computação para diferentes perfis e discutir sobre temas sociais relacionados às mulheres.

\section{Conclusão e Trabalhos futuros}

Este artigo abordou o Design Thinking como ferramenta de inovação tecnológica para o empoderamento feminino, por meio de oficinas ofertadas em diferentes eventos para públicos variados. A oficina possibilitou o debate sobre as dificuldades vividas por mulheres na sociedade e por meio de técnicas e ferramentas utilizadas no Design Thinking a prototipação de aplicativos que atuasse como um aliado no empoderamento feminino.

Os resultados indicaram uma percepção positiva dos participantes em relação às técnicas abordadas e como aplicá-las no processo do desenvolvimento de soluções tecnológicas, bem como idealizar soluções relacionadas aos temas propostos nas oficinas integrando a tecnologia ao protagonismo feminino. O projeto Meninas Digitais do Vale propiciou o desenvolvimento de ações dentro e fora do campus onde o projeto é realizado. As oficinas conduzidas por alunas permitiram experiência de ensino aprendizagem. A participação em eventos fora do campus permitiu uma maior integração a comunidade de mulheres na TI, ultrapassando as fronteiras da universidade.

Como trabalho futuro pretende-se aprimorar a oficina, como permitir que os protótipos sejam criados em plataformas que simulem as telas e interações básicas do usuário com os aplicativos, para assim deixá-los mais realísticos e analisar a satisfação do público feminino sobre a oficina já que nos resultados não houve distinção de gênero. Como o Design Thinking possui uma grande variedade de técnicas que podem ser adotadas, novas oficinas podem ser conduzidas com a aplicação de técnicas diferentes.

\section{Referências}

Fawcett, P., Fisher, K. E., Bishop, A. P., \& Magassa, L. (2013). Using design thinking to empower ethnic minority immigrant youth in their roles as technology and information mediaries. In CHI'13 Extended Abstracts on Human Factors in Computing Systems (pp. 361-366).

Louzada, C. S., Gomes, W. F., Nunes, M. A. S. N., Salgueiro, E. M., Andrade, B. T., \& Lima, P. (2014). Um mapeamento das publicações sobre o ingresso das mulheres na computação. In CLEI 2014: Conferência Latino-americana em Informática-VI Congresso da Mulher Latino-americana na Computação. Montevidéu (p. 16).

ONU Mulheres Brasil."Pensemos em igualdade, construção das mudanças com inteligência e inovação”.Disponível em: http://www.onumulheres.org.br/. Acesso em :12 de março de 2020.

Pagani,T. (2018). Design Thinking. Senac, São Paulo.

Vianna, M., Vianna, Y., Adler, I., Lucena, B., \& Russo, B. (2012). Design Thinking: Inovação em Negócios, MJV Press, Rio de Janeiro. 